\title{
Cinnamic acid based thiazolidinediones inhibit human P450c17 and 3ß-hydroxysteroid dehydrogenase and improve insulin sensitivity independent of PPAR $\gamma$ agonist activity
}

\author{
Weibke Arlt*, Partha Neogi ${ }^{1 *}$, Coleman Gross ${ }^{1}$ and Walter L Miller \\ Department of Pediatrics and the Metabolic Research Unit, University of California, San Francisco, California 94143-0978, USA \\ ${ }^{1}$ Calyx Therapeutics, Inc., Hayward, California 94545, USA \\ (Requests for offprints should be addressed to Walter L Miller, Department of Pediatrics, Bldg MR-IV, Rm 209, University of California, San Francisco, \\ California 94143-0978, USA; Email: wlmlab @itsa.ucsf.edu) \\ *(Weibke Arlt and Partha Neogi contributed equally to this work)
}

\begin{abstract}
Thiazolidinediones improve insulin sensitivity in type 2 diabetes mellitus by acting as peroxisome proliferator-associated receptor gamma (PPAR $\gamma$ ) agonists, and decrease circulating androgen concentrations in polycystic ovary syndrome by unknown mechanisms. Some thiazolidinediones directly

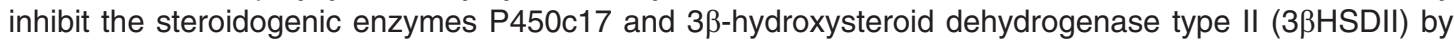
distinct mechanisms. We synthesized five novel thiazolidinediones, CLX-M1 to -M5 by linking a 2,4-thiazolidinedione moiety to a substituted $\alpha$-phenyl cinnamic acid previously shown to have glucose-lowering effects. Using yeast microsomes expressing human P450c17 and 3BHSDII we found that cinnamic acid methyl esters with a double bond in the thiazolidinedione core structure (M3, M5) were stronger inhibitors of P450c17 than methyl esters with the conventional core (M1, M4). These four compounds inhibited $3 \beta \mathrm{HSDII}$ equally well, while the free cinnamic acid analog (M2) did not inhibit either enzyme. Thus, the inhibition of P450c17 and 3BHSDII by these novel thiazolidinediones reveals structure-activity relationships independent of PPAR $\gamma$ transactivation. PPAR $\gamma$ transactivation was moderate (M1), weak (M2, M3) or even absent (M4, M5). While the PPAR $\gamma$ agonist activity of M1 was only $3 \%$ of that of rosiglitazone, both increased glucose uptake by 3T3-L1 adipocytes and reduced serum glucose levels in $o b / o b$ and $d b / d b$ mice to a similar extent. The similar glucose-lowering effects of M1 and rosiglitazone, despite their vast differences in PPAR $\gamma$ agonist activity, suggests these two actions may occur by separate mechanisms.
\end{abstract}

Journal of Molecular Endocrinology (2004) 32, 425-436

\section{Introduction}

Thiazolidinediones (TZDs), a recently introduced class of drugs (Schoonjans \& Auwerx 2000), decrease hepatic gluconeogenesis and improve insulin sensitivity, particularly in adipose tissue (Lehmann et al. 1995, Spiegelman 1998, Olefsky 2000) and hence are useful in treating type 2 diabetes. The TZD drug troglitazone improves both insulin sensitivity and hyperandrogenemia in women with the polycystic ovary syndrome (PCOS) (Dunaif et al. 1996, Azziz et al. 2001). PCOS is a heterogeneous disorder, variably consisting of menstrual irregularities and hyperandrogenemia, and is the leading cause of female infertility (Ehrmann et al. 1995, Dunaif \& Thomas 2001). PCOS is frequently associated with obesity, insulin resistance and increased risk of type 2 diabetes (Ehrmann et al. 1995, Franks 1995, Dunaif \& Thomas 2001). While the insulin-sensitizing effects of TZD drugs are clearly associated with their action as agonists of the nuclear peroxisome proliferator-associated receptor gamma (PPAR $\gamma$ ) (Lehmann et al. 1995), the mechanism by which they lower circulating androgen concentrations is less clear. The androgen-lowering effect of 
troglitazone has been thought to be secondarily due to its insulin-sensitizing effect (Dunaif et al. 1996, Ehrmann et al. 1997). However, we have recently demonstrated that troglitazone also directly inhibits the catalytic activities of two key enzymes in human androgen biosynthesis (Arlt et al. 2001). Troglitazone at concentrations achieved in clinical use competitively inhibits both the $17 \alpha$-hydroxylase and 17,20-lyase activities of P450c17 and noncompetitively inhibits $3 \beta$-hydroxysteroid dehydrogenase type 2 (3ßHSDII) (Arlt et al. 2001). Two other TZDs, rosiglitazone and pioglitazone, also inhibited both P450c17 and 3ßHSD but only at supra-pharmacologic concentrations (Arlt et al. 2001). Thus, inhibition of $\mathrm{P} 450 \mathrm{c} 17$ and $3 \beta \mathrm{HSD}$ may be a general characteristic of TZD drugs, possibly independent of PPAR $\gamma$ agonist activity.

We previously reported that a substituted $\alpha$-phenyl cinnamic acid derivative exerts weak antihyperglycemic effects in several animal models, possibly by an interaction with the insulin receptor (Dey et al. 1999, 2001). We hypothesized that linking this molecule with a 2,4-TZD moiety might generate bifunctional molecules that exert hypoglycemic actions by interacting with both the insulin receptor and PPAR $\gamma$. Thus we synthesized five novel cinnamic or phenyl propionic acid based 2,4-TZD derivatives and investigated their PPAR $\gamma$ agonist activity, their glucose-lowering effects in vitro and in vivo, and their ability to inhibit $\mathrm{P} 450 \mathrm{c} 17$ or 3ßHSD.

\section{Materials and methods}

\section{Drug preparations}

Reagent-grade 2,4-TZD derivatives of cinnamic acid were synthesized and purified. Rosiglitazone was purified from commercially available tablets (Avandia, Smith Kline Beecham). The chemical equivalence and purity of the novel TZDs and of rosiglitazone prepared from tablets were confirmed by their HPLC and ${ }^{1} \mathrm{H}-\mathrm{NMR}$ analysis.

\section{Transfection of HEK293 cells and reporter gene assay for PPAR $\gamma$ agonist activity}

A PPAR $\gamma 2$ expression vector was constructed by inserting the PPAR $\gamma 2$ coding region into pcDNA3 $1+$ vector (Invitrogen, Carlsbad, CA, USA). The luciferase reporter vector was con- structed by ligating a PPRE response element (a gift from K. Feingold, San Francisco VA Medical Center, CA, USA) upstream from the firefly luciferase coding region. Control vector pRL-SV40 expressing Renilla luciferase was purchased from Promega (Madison, WI, USA).

About $2.7 \times 10^{4}$ HEK293 cells (ATCC, Manassas, VA, USA) were plated onto a $35 \mathrm{~mm}$ culture well and maintained in Eagle's Minimal Essential Medium (EMEM, ATCG, Manassas, VA, USA) supplemented with $10 \%$ heat inactivated horse serum (ATCG) for $24 \mathrm{~h}$. The expression, reporter and control vectors $(2.5 \mathrm{ng}$ control and 100 ng others per culture well) were transfected by lipofectamine reagent (Invitrogen, Carlsbad, CA, USA). Transfection reagent and DNA were prepared according to the manufacturer's recommendations and incubated with cells for $3 \mathrm{~h}$ followed by adding an equal volume of EMEM supplemented with $20 \%$ horse serum. Twenty-four hours after transfection, cells were treated with vehicle or TZD compounds at the indicated final concentrations for $24 \mathrm{~h}$. The final concentration of DMSO in the medium was $0.01 \%$. Treatments with vehicle or compound were all conducted in triplicate. Each culture well was then assayed for firefly luciferase activity and Renilla luciferase using the Dual-luciferase Reporter Assay System (Promega). Final reporter activity was calculated as the ratio of firefly luciferase activity to Renilla luciferase activity.

\section{Enzyme preparations}

Saccharomyces cerevisiae strain W303B (Pompon et al. 1996) was transformed by the lithium acetate procedure (Gietz et al. 1992) with the yeast expression vector V10 (Pompon et al. 1996) containing the cDNA sequences for human P450c17 or 33HSDII, as described previously (Auchus et al. 1998, Lee et al. 1999). For transformation with P450c17, yeast were co-transformed with the vector pYcDE2 (Hadfield et al. 1986) expressing human P450 oxidoreductase cDNA (Auchus et al. 1998).

\section{Enzyme assays}

Yeast microsomes were incubated in $0-100 \mu \mathrm{M}$ of each TZD drug. Compounds were dissolved in DMSO, and $4 \mu \mathrm{l}$ DMSO containing the respective 
amount of CLX-M1-M5 were added to $196 \mu \mathrm{l}$ of a $50 \mathrm{mM}$ potassium phosphate buffer $(\mathrm{pH} 7 \cdot 5)$. Enzymatic assays were performed with $1 \mu \mathrm{M}$ progesterone or 17 $\alpha$-hydroxypregnenolone for P450c17 activities and $5 \mu \mathrm{M}$ pregnenolone for $3 \beta$ HSDII activity. These steroid substrate concentrations are above the apparent $K_{\mathrm{m}}$ values of the respective enzymes in this system (Auchus et al. 1998, Lee et al. 1999). Each reaction contained 20000 c.p.m. of $\left[{ }^{14} \mathrm{C}\right]$-pregnenolone $(55 \cdot 4 \mathrm{mCi} /$ mmol) (Amersham, Arlington Heights, IL, USA) for analysis of $3 \beta \mathrm{HSDII}$ activity, 20000 c.p.m. of $\left[{ }^{14} \mathrm{C}\right]$-progesterone $(55.4 \mathrm{mCi} / \mathrm{mmol})$ (NEN Life Science Products, Boston, MA, USA) for $17 \alpha-$ hydroxylase activity or 100000 c.p.m. of $\left[{ }^{3} \mathrm{H}\right] 17$ Preg $(21 \cdot 1 \mathrm{Ci} / \mathrm{mmol})$ (NEN Life Science Products) for 17,20-lyase activity. Catalysis was initiated by adding $1 \mathrm{mM}$ NADPH for P450c17 or $1 \mathrm{mM}$ $\mathrm{NAD}^{+}$for $3 \beta \mathrm{HSDII}$ activity, and assays were carried out in the linear time range of the enzymatic reaction. Assays of 17,20-lyase activity were performed with addition of purified recombinant human cytochrome $b_{5}$ (PanVera, Madison, WI, USA).

Steroids were extracted from the reaction mixtures with $400 \mu \mathrm{l}$ ethyl acetate/isooctane (1:1), concentrated by evaporation under continuous nitrogen flow, and assayed by thin layer chromatography (TLC) on PE SIL G/u.v. silica gel plates (Whatman, Maidstone, UK) using 3:1 chloroform:ethyl acetate as the solvent system (Lin et al. 1991). Substrates and conversion products were identified by comparison with reference steroids and quantified by phosphorimager analysis on a Storm 860 PhosphorImager (Molecular Dynamics, Sunnyvale, CA, USA). The percentage of transformation, the residual percentage of enzymatic activity after inhibitor administration (=\%baseline activity), and the percentage of inhibition were calculated from the equation $(\%$ baseline activity $=\%$ transformation with inhibitor $\%$ transformation without inhibitor $\times$ 100).

\section{Basal glucose uptake by 3T3-L1 adipocytes}

Basal glucose uptake was measured in 3T3-L1 adipocytes (Tafuri 1996). 3T3-L1 fibroblasts were procured from ATCG (Manassas, VA, USA) and differentiated to adipocytes by treating cells with porcine insulin ( $1 \mu \mathrm{g} / \mathrm{ml}$ for 4 days), dexametha- sone $(0.25 \mu \mathrm{M}$ for the initial 2 days $)$ and isobutyl methyl xanthine $(0.5 \mathrm{mM}$ for the initial 2 days (all from Sigma Chemicals, St Louis, MO, USA) (Frost \& Lane 1985). The differentiated adipocytes were incubated in DMEM containing 10\% fetal bovine serum (Gibco) with either rosiglitazone or compounds M1-M5 $(0 \cdot 1$ and $1 \cdot 0 \mu \mathrm{M})$ or vehicle $(0 \cdot 1 \% \mathrm{DMSO})$ for $48 \mathrm{~h}$ in 24 -well plates. The cells were then washed with phosphate-buffered saline and incubated in glucose-free DMEM containing $1 \cdot 0 \% \mathrm{BSA}$ for $1 \mathrm{~h}$ at $37{ }^{\circ} \mathrm{C}$, then ${ }^{14} \mathrm{C}$-deoxyglucose (300 $\mathrm{mCi} / \mathrm{mmol}$ American Radiolabeled Chemicals Inc., St Louis, MO, USA) was added and the cells were incubated for another $10 \mathrm{~min}$ at room temperature. The cells were then washed three times with ice cold Dulbecco's PBS containing $10 \mathrm{mM}$ cold deoxyglucose, lysed with $0.5 \% \mathrm{SDS}$, and counted in a scintillation counter. All assays were performed in triplicate.

\section{In vivo studies}

All procedures performed were in compliance with the Animal Welfare Act and US Department of Agriculture regulations and were approved by the Calyx Therapeutics Institutional Animal Care and Use Committee. Animals were housed at $22{ }^{\circ} \mathrm{C}$ and $50 \%$ relative humidity, with a $12 \mathrm{~h}$ light : $12 \mathrm{~h}$ darkness cycle, and received a regular rodent diet (Harlan Teklad, Madison, WI, USA) with free access to water; food was available ad libitum. Male $\mathrm{C} 57 \mathrm{BL} / \mathrm{KsJ}-d b / d b$ and C57BL/6J-ob/ob mice were obtained from Jackson Laboratories (Bar Harbor, ME, USA) at age 5 weeks. Seven- to 8-week-old animals were given compound $\mathrm{M} 1$, rosiglitazone or vehicle $(0 \cdot 5 \%$ carboxymethyl cellulose (CMC), Sigma) in water or $0.5 \% \mathrm{CMC}$ in water containing $10 \%$ PEG-300 orally once daily by gavage. Blood glucose levels were monitored at $0,1,4,6,24,48$ and $72 \mathrm{~h}$ with a One Touch Glucose Meter (Life Scan, Inc., Milpitas, CA, USA) and/or a glucose oxidase assay (Glucose Trinder, Sigma) prior to administration of the next dose or $24 \mathrm{~h}$ after the last dose and in the fed state. Body weights were monitored throughout the study.

\section{Hepatic cytochrome P450 inhibition assay}

The activities of hepatic cytochrome P450 enzymes, including those that metabolize rosiglitazone, were measured using established assays 
<smiles>CCc1ccc(CCOc2ccc(CC3SC(=O)NC3=O)cc2)nc1</smiles>

Pioglitazone<smiles>CCC(=Cc1cc(OC)cc(OC)c1)C(=O)OC</smiles>

CLX-M1<smiles>CC=CC=C(C(=O)OC)C(=Cc1cc(OC)cc(OC)c1)c1ccc(Oc2ccc(C=C3SC(=O)NC3=O)cc2)cc1</smiles>

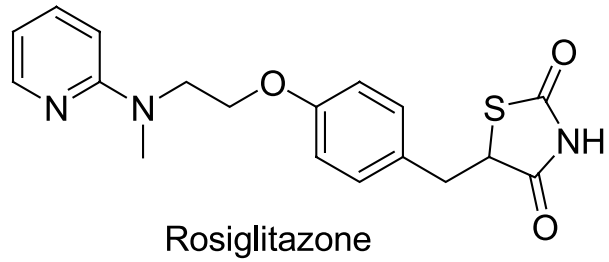<smiles>COc1cc(/C=C(/C(=O)O)c2ccc(O)cc2)cc(OC)c1</smiles>

Substituted alpha-phenylcinnamic acid<smiles>CCC(=Cc1cc(OC)cc(OC)c1)C(=O)OCCCCC(=O)OCCc1ccc(Oc2ccc(CC3SC(=O)NC3=O)cc2)cc1</smiles><smiles>COC(=O)C(Cc1cc(OC)cc(OC)c1)c1ccc(Oc2ccc(CC3SC(=O)NC3=O)cc2)cc1</smiles>

Double bond:

Ester group:<smiles>COC</smiles>
Me<smiles>COc1cc(C)cc(CC(C(C)=O)c2ccc(Oc3ccc(/C=C4\SC(=O)NC4=O)cc3)cc2)c1</smiles>

CLX-M5 
Table 1 Differential effects of compounds M1 to M5 and rosiglitazone on PPAR $\gamma$ transactivation as assessed by luciferase reporter gene assay, glucose uptake by 3T3-L1 adipocytes, and inhibition of enzymatic activities of the steroidogenic enzymes P450c17 and of 3 $3 \mathrm{HSD}$ expressed in yeast microsomes

\begin{tabular}{|c|c|c|c|c|c|c|}
\hline \multirow[b]{2}{*}{ Compound } & \multirow{2}{*}{$\begin{array}{l}\text { PPAR } \gamma \\
\text { transactivation } \\
\mathrm{EC}_{50}(\mu \mathrm{M}) \pm \mathrm{SD}\end{array}$} & \multicolumn{2}{|c|}{$\begin{array}{l}\% \text { glucose } \\
\text { uptake } \pm \text { SD }\end{array}$} & \multicolumn{3}{|c|}{$\begin{array}{l}\text { Inhibition of steroidogenic } \\
\text { enzymes } I_{50}(\mu M)\end{array}$} \\
\hline & & $0.1 \mu \mathrm{M}$ & $1.0 \mu \mathrm{M}$ & $17 \alpha$-hydroxylase & 17.20-lyase & $3 \beta \mathrm{HSD}$ \\
\hline $\begin{array}{l}\text { Rosiglitazone } \\
\text { M1 }\end{array}$ & $\begin{array}{l}0.01 \pm 0.007 \\
0.28 \pm 0.036\end{array}$ & $\begin{array}{l}204 \pm 8 \cdot 5 \\
161 \pm 11 \cdot 4\end{array}$ & $\begin{array}{l}214 \pm 36 \cdot 5 \\
218 \pm 10 \cdot 0\end{array}$ & $\begin{array}{l}86 \\
56\end{array}$ & $\begin{array}{l}90 \\
>100\end{array}$ & $\begin{array}{l}54 \\
16\end{array}$ \\
\hline M2 & $0.69 \pm 0.038$ & $109 \pm 19.9$ & $200 \pm 11 \cdot 6$ & - & - & - \\
\hline M3 & 1.14 & $143 \pm 7 \cdot 4$ & $209 \pm 22 \cdot 6$ & 32 & 85 & 9 \\
\hline M4 & $57 \cdot 7$ & $104 \pm 5 \cdot 7$ & $137 \pm 10 \cdot 1$ & 69 & $>100$ & 20 \\
\hline M5 & 23.9 & $102 \pm 6 \cdot 8$ & $130 \pm 27 \cdot 0$ & 28 & 72 & 16 \\
\hline
\end{tabular}

(Baldwin et al. 1999, Crespi \& Miller 1999, Nakajima et al. 1999). Six pre-warmed reaction vials with $100 \mu \mathrm{l}$ of a solution containing $50 \mathrm{mM}$ potassium phosphate, $\mathrm{pH} 7 \cdot 4,2 \cdot 6 \mathrm{mM} \mathrm{NADP}+$, $6.6 \mathrm{mM}$ glucose 6-phosphate, $0.8 \mathrm{U}$ of glucose 6-phosphate dehydrogenase/ml and a 1:6 serial dilution of the test compound were prepared along with six tubes of a 1:6 serial dilution of a suitable positive control inhibitor. The reactions were initiated by adding $100 \mu \mathrm{l}$ of a prewarmed solution of recombinant enzyme (purchased from Gentest, Woburn, MA, USA) and substrate (purchased either from Gentest or Sigma) in 0.05-0.35 M potassium phosphate, $\mathrm{pH} 7 \cdot 4$. A zero time-point control reaction was prepared by adding $40 \mu \mathrm{l}$ of acetonitrile to $100 \mu \mathrm{l}$ of cofactor solution to inactivate the enzymes, then adding $100 \mu \mathrm{l}$ of enzyme/substrate solution. A control reaction with no inhibitor was also prepared. After a 10-min incubation at $37^{\circ} \mathrm{C}$, the reactions were terminated by the addition of $40 \mu \mathrm{l}$ of acetonitrile. The reactions were centrifuged for $3 \mathrm{~min}$ and the supernatants were analyzed for the metabolite and/or parent forms of the probe substrate using an RPAmide C16 column maintained at $40^{\circ} \mathrm{C}$. The probe substrates and metabolites were detected by HPLC-u.v. Each assay was performed in duplicate. The enzyme-substrate and control inhibitor combinations are as follows: CYP1A2 $(20 \mathrm{nM})$-phenacetin $(10 \mu \mathrm{M})$-furafylline $(0 \cdot 0026$ $3.33 \mu \mathrm{M})$; CYP2A6 (13 $\mathrm{nM})$-coumarin $(10 \mu \mathrm{M})-$ tranylcypromine $\quad(0 \cdot 0064-50 \mu \mathrm{M}) ; \quad$ CYP2C8
$(100 \mathrm{nM})-$ paclitaxel $\quad(10 \mu \mathrm{M})-$ quercetin $\quad(0 \cdot 013-$ 16.67 $\mu \mathrm{M})$; CYP2C9 (20 nM)-diclofenac $(20 \mu \mathrm{M})$ sulaphenazole $\quad(0 \cdot 0064-50 \mu \mathrm{M}) ; \quad$ CYP2C19 $(100 \mathrm{nM})-(\mathrm{S})$-mephenytoin $\quad(100 \mu \mathrm{M})-$ tranylcypromine $(0 \cdot 064-500 \mu \mathrm{M}) ; \quad$ CYP2D6 $(20 \mathrm{nM})-$ dextromethorphan $(14 \mu \mathrm{M})-$-quinidine $(0 \cdot 0013-$ $1.67 \mu \mathrm{M})$; CYP2E1 (200 $\mathrm{nM})$-chlorzoxazone $(50 \mu \mathrm{M})$-4-methylpyrazole $\quad(0 \cdot 013-16 \cdot 67 \mu \mathrm{M})$; CYP3A4 $(8,13$ or $13 \mathrm{nM})$-midazolam $(6 \mu \mathrm{M})$, testosterone $(100 \mu \mathrm{M})$ or nifedipine $(20 \mu \mathrm{M})-$ ketoconazole $(0.0013-1.67 \mu \mathrm{M})$. The final concentrations of $\mathrm{M} 1$ and M2 were 0.0064, 0.039, 0.23, $1 \cdot 39,8 \cdot 33$ and $50 \mu \mathrm{M}$.

\section{Results}

\section{Structural features of the cinnamic acid based TZDs}

The five compounds are 2,4-TZD derivatives of cinnamic or phenyl propionic acid (Fig. 1). Analogs M1, M2 and M3 are cinnamic acid derivatives and M4 and M5 are phenyl propionic acid derivatives. Compounds M1, M3, M4 and M5 are methyl esters and M2 is the corresponding free acid of M1. In M3 and M5, the TZD ring is connected to rest of the molecule with a double bond instead of a single bond as in M1, M2 and M4.

\section{PPAR $\gamma$ transactivation assay}

Using a luciferase reporter assay, we determined PPAR $\gamma$ agonist activity of the five novel TZDs

Figure 1 Chemical structures of the established TZD compounds pioglitazone, rosiglitazone and troglitazone, of an $\alpha$-phenyl substituted cinnamic acid derivative, and of the five novel cinnamic acid based 2,4-TZD analogs, CLX-M1 to -M5. The closed and open arrows indicate the double bonds and ester groups discussed in the text. 
(Table 1). The most potent compound in this series was $\mathrm{M} 1\left(\mathrm{EC}_{50}\right.$ of $\left.0.28 \mu \mathrm{M}\right)$, which had one-thirtieth the activity of rosiglitazone $\left(\mathrm{EC}_{50}\right.$ of $\left.0.009 \mu \mathrm{M}\right)$ in the same assay. Compounds M2 and M3 also showed reasonable potency, though less than M1. Compounds M4 and M5, in which the cinnamic acid double bond was reduced, were essentially inactive. Thus the presence of the cinnamic acid double bond is essential for the maintenance of $\operatorname{PPAR} \gamma$ agonist activity.

\section{Assays of P450c17 and 3ßHSD activities}

P450c17 catalyzes both 17 $\alpha$-hydroxylase and 17,20-lyase activities, and is required for biosynthesis of human androgens (Nakajin et al. 1981, Zuber et al. 1986, Lin et al. 1991). The 17a-hydroxylase activity of human $\mathrm{P} 450 \mathrm{c} 17$ converts pregnenolone to $17 \alpha-\mathrm{OH}$-pregnenolone (17-Preg) and progesterone to $17 \alpha-\mathrm{OH}$-progesterone (17 OHP) with equivalent efficiencies (Auchus et al. 1998). However, the 17,20-lyase activity is 30-50-fold more effective in converting 17-Preg to DHEA than in converting $17 \mathrm{OHP}$ to androstenedione (Lin et al. 1993, Auchus et al. 1998). Each catalytic cycle of $\mathrm{P} 450 \mathrm{c} 17$ requires electron donation from $\mathrm{P} 450$ oxidoreductase, with cytochrome $b_{5}$, allosterically facilitating the 17,20-lyase reaction but not the $17 \alpha$-Hydroxylase reaction (Auchus et al. 1998). Therefore, all P450c17 assays were carried out with microsomes from yeast co-transformed with vectors expressing human $\mathrm{P} 450 \mathrm{c} 17$ and human oxidoreductase (Auchus et al. 1998, Arlt et al. 2001). $17 \alpha$-hydroxylase activity was measured as the conversion of progesterone to $17 \mathrm{OHP}$, which is not metabolized further, and 17,20-lyase activity was measured as the conversion of 17-Preg to DHEA in the presence of cytochrome $b_{5}$.

Two catalytically equivalent forms of $3 \beta$ hydroxysteroid dehydrogenase (3ßHSD) catalyze the conversions of pregnenolone to progesterone, of 17-Preg to $17 \mathrm{OHP}$ and of DHEA to androstenedione (Thomas et al. 1989, Rhéaume et al. 1992). Androstenedione, in turn, is converted to testosterone and dihydrotestosterone, which bind to and activate the androgen receptor. We measured $3 \beta \mathrm{HSD}$ activity in microsomes of transformed yeast as the conversion of pregnenolone to progesterone, which also reflects the rate of conversion of DHEA to androstenedione because all three substrates for $3 \beta \mathrm{HSD}$ have equivalent apparent $K_{\mathrm{m}}$ and similar
$V_{\max }$ values in our yeast expression system (Lee et al. 1999).

Compounds M3 and M5 readily inhibited the $17 \alpha$-hydroxylase activity in a dose-dependent manner, whereas M1 and M4 were less effective and M2 had virtually no inhibitory effect (Fig. 2A). The $\mathrm{IC}_{50}$ values for M3 and M5 were $28-32 \mu \mathrm{M}$, and those for $\mathrm{M} 1$ and M4 were 56 and $69 \mu \mathrm{M}$ respectively, whereas and $\mathrm{IC}_{50}$ value for $\mathrm{M} 2$ could not be calculated (Table 1). A similar pattern was seen with the 17,20-lyase activity of P450c17. M3 and M5 were better inhibitors than M1 and M4, while M2 exhibited virtually no inhibitory effect (Fig. 2B and Table 1). By contrast, the $\mathrm{IC}_{50}$ values for the two P450c17 activities were $86-90 \mu \mathrm{M}$ for rosiglitazone and $>100 \mu \mathrm{M}$ for pioglitazone, but only 11-12 $\mu \mathrm{M}$ for troglitazone (Arlt et al. 2001).

The effects on $3 \beta \mathrm{HSD}$ activity were somewhat different (Fig. 3). All the cinnamic or phenyl propionic acid methyl esters (M1, M3, M4 and M5) were effective $3 \beta \mathrm{HSD}$ inhibitors, with $\mathrm{IC}_{50}$ values ranging from 9 to $20 \mu \mathrm{M}$ (Table 1), while M2, the free cinnamic acid derivative, again was devoid of inhibitory activity. Thus the $3 \beta \mathrm{HSD}$ inhibitory activity of the cinnamic acid methyl ester TZDs was equal to or greater than that of troglitazone $\left(\mathrm{IC}_{50}=24 \mu \mathrm{M}\right)$ (Arlt et al. 2001), but the inhibitory activity of the free acid derivative was less than that of rosiglitazone and similar to that of pioglitazone (Arlt et al. 2001). Thus the methyl group, which is present in all compounds but M2, seems to be of crucial importance for the inhibition of both P450c17 and 3ßHSD. Furthermore, the introduction of a double bond into the conventional TZD core structure in M3 and M5 results in significantly enhanced inhibition of $17 \alpha$-hydroxylase activity.

\section{Glucose uptake by 3T3-L1 adipocytes}

Glucose uptake by adipocytes was measured by incorporation of ${ }^{14} \mathrm{C}$-deoxyglucose into 3T3-L1 cells, which had first been induced to differentiate from fibroblasts to adipocytes by treatment with insulin, dexamethasone and methylxanthine (Frost \& Lane 1985). Adding $1 \cdot 0 \mu \mathrm{M}$ of compounds M1, M2, M3 or rosiglitazone doubled glucose uptake by 3T3-L1 cells while compounds M4 and M5 had minimal activity (Table 1 ). At $0 \cdot 1 \mu \mathrm{M}$, compounds M1 and M3 retained some activity, but less than that of rosiglitazone, while the other compounds were inactive. Compounds M1 and M3 differ in the 


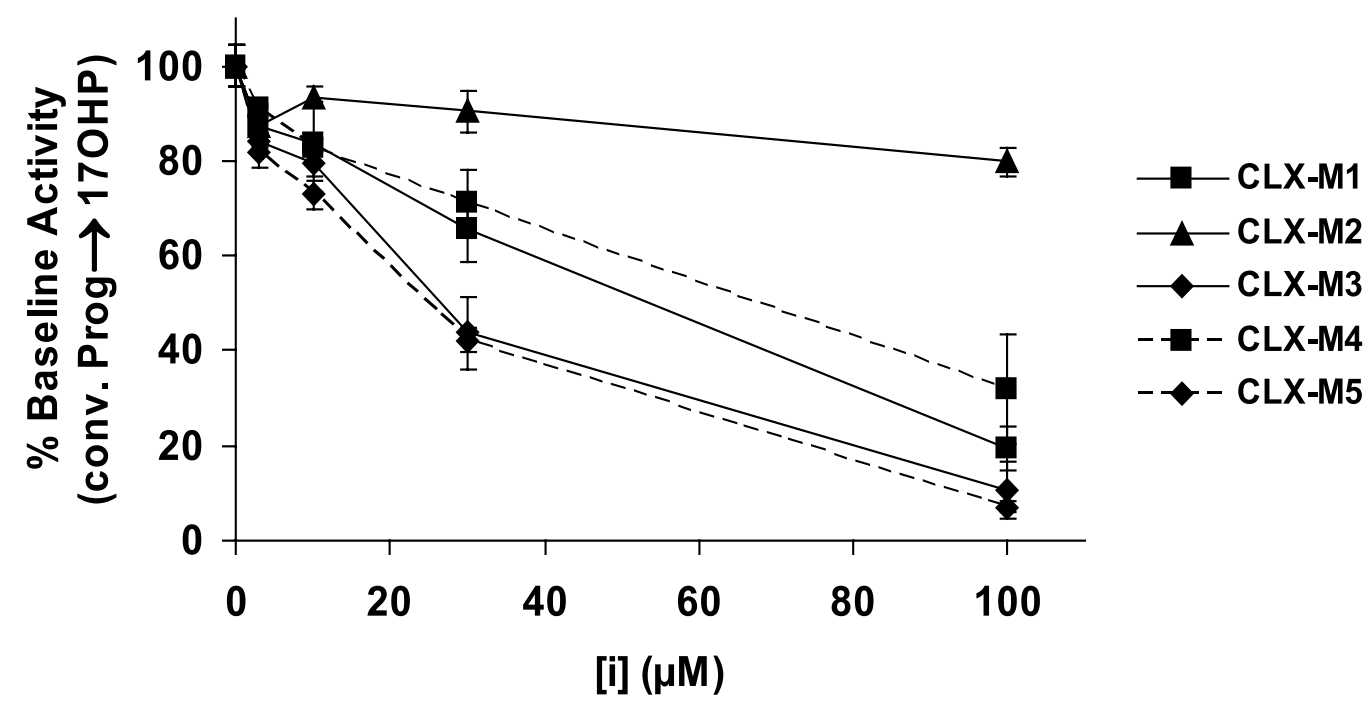

B

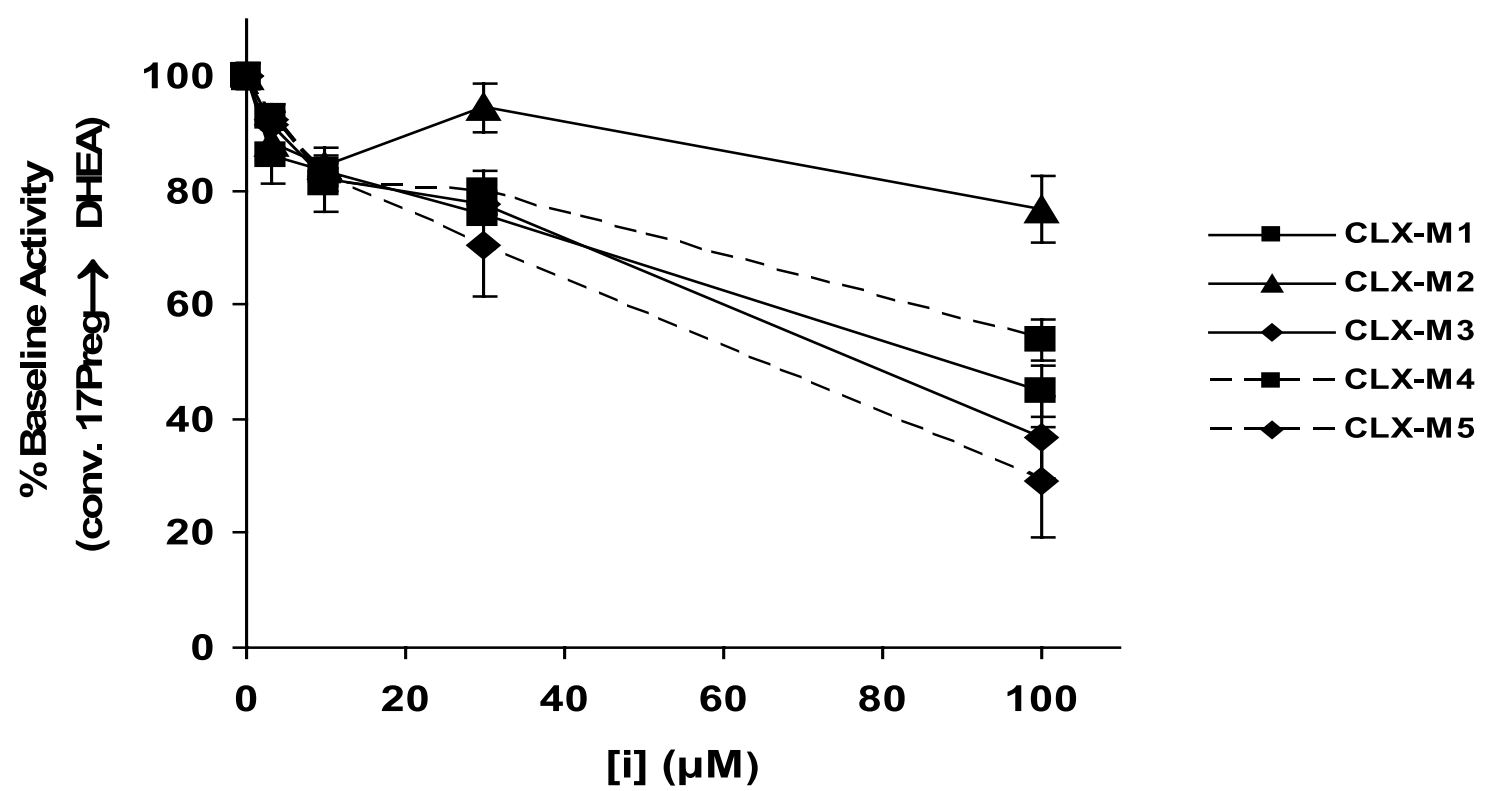

Figure 2 Effect of CLX-M1 to -M5 on the activities of human P450c17. (A) 17 $\alpha$-Hydroxylase activity. Microsomes prepared from yeast co-expressing human P450c17 and human P450 oxidoreductase were incubated with $1 \mu \mathrm{M}\left[{ }^{14} \mathrm{C}\right]$ progesterone (Prog) and 0-100 $\mu \mathrm{M}$ of CLX-M1 to $-\mathrm{M} 5$. $17 \alpha$-Hydroxylase activity was assessed as the conversion rate of Prog to $17 \mathrm{OHP}$. (B) 17,20-Lyase activity. Microsomes co-expressing P450c17 and oxidoreductase were incubated with $1 \mu \mathrm{M}\left[{ }^{3} \mathrm{H}\right] 17 \alpha$-hydroxypregnenolone (17-Preg) and 0-100 $\mu \mathrm{M}$ CLX-M1 to -M5. 17,20-Lyase activity was assessed as the conversion rate of 17-Preg to DHEA. Each data point represents the mean \pm S.D. of triplicate determinations. 


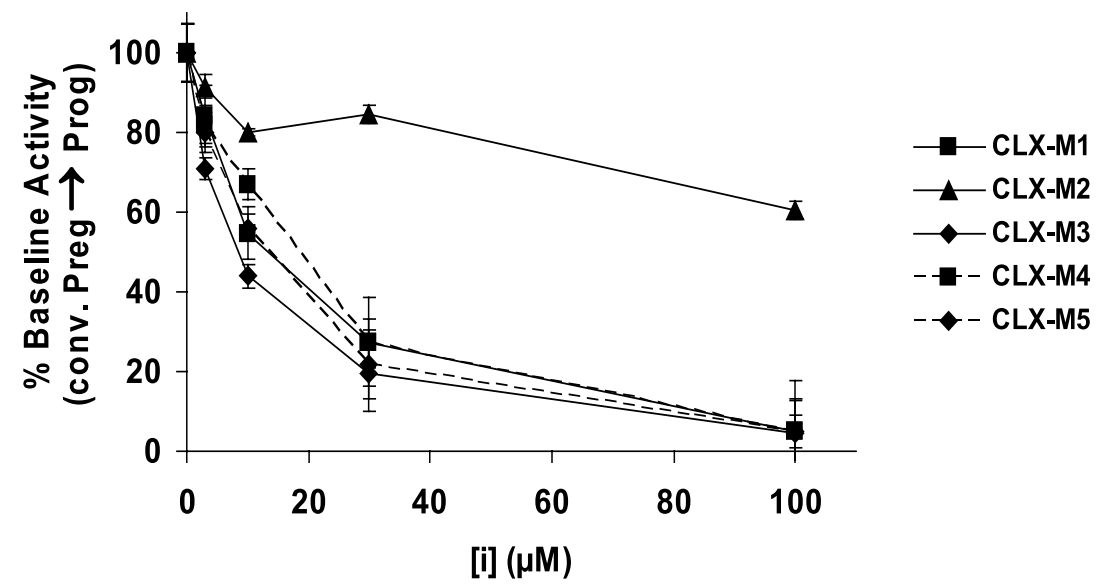

Figure 3 Effect of CLX-M1 to -M5 on 3ßHSDII activity. Microsomes prepared from yeast expressing human $3 \beta \mathrm{HSDII}$ were incubated with $5 \mu \mathrm{M}$ $\left[{ }^{14} \mathrm{C}\right]$ pregnenolone (Preg) and $0-100 \mu \mathrm{M}$ of CLX-M1 to -M5. 3BHSDII activity was assessed as the conversion rate of Preg to progesterone (Prog). Each data point represents the mean \pm S.D. of triplicate determinations.

double bond in the glitazone moiety and had significantly different PPAR $\gamma$ agonist activities, but had minimal differences in their ability to induce glucose uptake (no statistically significant differences by ANOVA). Compound M5, with only one double bond joined to the TZD ring, and the doubly reduced product M4 were devoid of activity at $0 \cdot 1 \mu \mathrm{M}$. Thus, the absence of the double bond joined to the TZD ring and the presence of the cinnamic acid double bond seem to be important for increased glucose uptake in this system.

\section{Effects of M1 in mouse models of type 2 diabetes}

Because the in vitro assays described above indicated that compound $\mathrm{Ml}$ exerts the greatest PPAR $\gamma$ agonist activity and the greatest activity to promote glucose uptake while exerting low inhibitory activity against steroidogenic enzymes, we sought to evaluate compound $\mathrm{M} 1$ in mouse models of type 2 diabetes. The genetically obese, diabetic $o b / o b$ mouse, which is defective in leptin synthesis, and the genetically hyperinsulinemic diabetic $d b / d b$ mouse, which is defective in the leptin receptor, are well-established models of type 2 diabetes (Primer 2000). A single oral dose of $50 \mathrm{mg} / \mathrm{kg}$ of compound M1 lowered blood glucose in $d b / d b$ mice in a time-dependent fashion, reaching a nadir of $23 \%$ of the control value after $24 \mathrm{~h}$ (data not shown). When administered orally once daily ( $50 \mathrm{mg} / \mathrm{kg}$ per day) for 14 days to $d b / d b$ mice, compound M1 and rosiglitazone exhibited equivalent effects to lower blood glucose (Fig. 4A) but neither compound affected body weight (Fig. 4B). Similar results are seen in ob/ob mice, in which M-1 $(10 \mathrm{mg} / \mathrm{kg}$ per day) and rosiglitazone (10 $\mathrm{mg} / \mathrm{kg}$ per day) lowered blood glucose by $47 \%$ and $53 \%$ respectively after 8 days, compared with vehicle.

\section{Effects of M1 and M2 on hepatic cytochrome P450 enzymes}

Due to severe idiosyncratic hepatocellular injury, troglitazone has been withdrawn from the market. This toxicity may originate from inhibition of hepatic cytochrome P450 enzymes by troglitazone and its two metabolites (Yamazaki et al. 2000). Thus, we studied the potential effects of $\mathrm{Ml}$ and its free acid form M2 on hepatic cytochrome P450 enzymes. M2 is the primary metabolite of M1 in most species including humans. The metabolism of about $90 \%$ of the clinically important pharmaceutical drugs is carried out by only eight cytochrome P450 enzymes: CYP1A2, CYP2A6, CYP2C8, CYP2C9, CYP2C19, CYP2D6, CYP2E1 and CYP3A4 (Rendic and Di Carlo 1997, Obach 1999). Compound M1 did not inhibit GYP1A2, and it had a low inhibitory effect $\left(\mathrm{IC}_{50}>15 \mu \mathrm{M}\right)$ on 


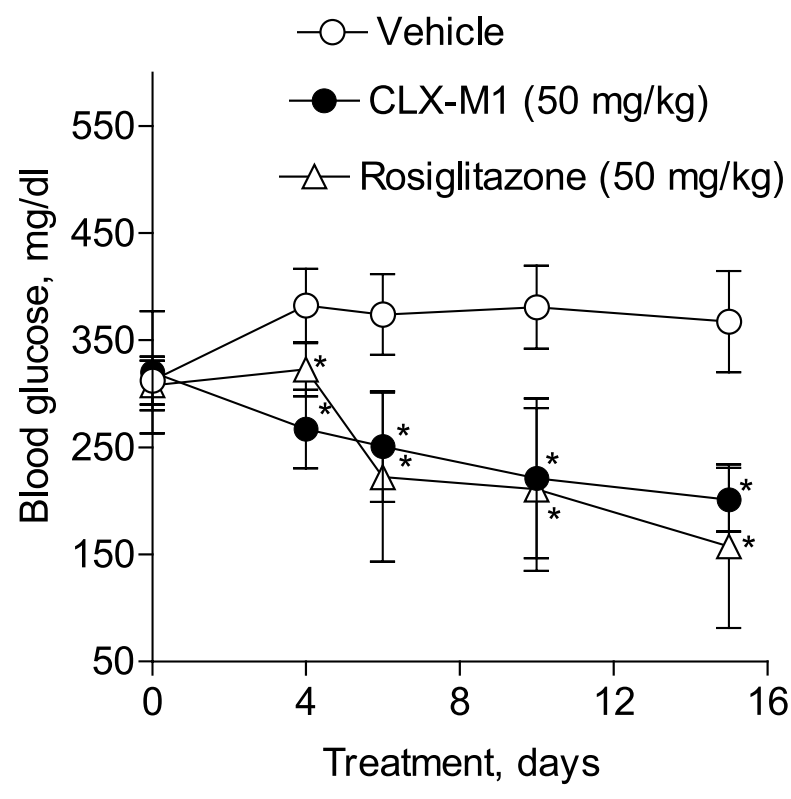

B

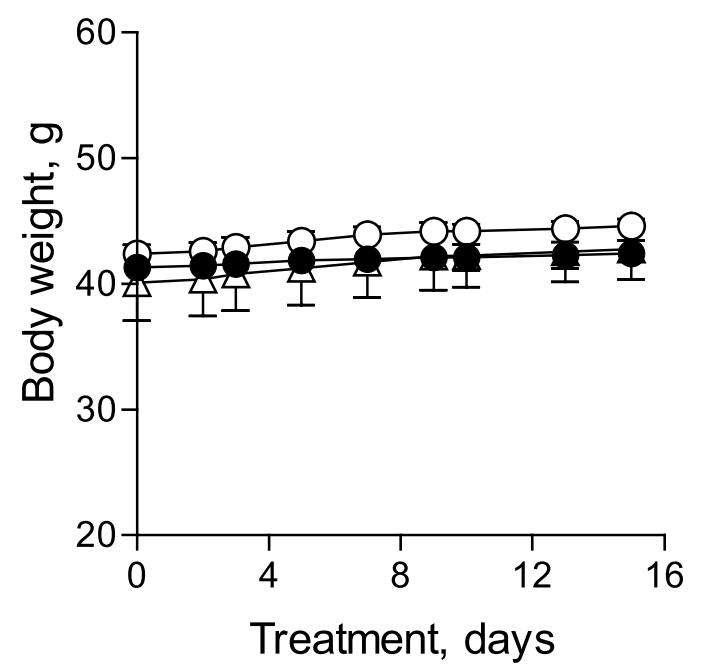

Figure 4 Effects of 2 weeks of treatment in 8-week-old male $d b / d b$ mice with $50 \mathrm{mg} / \mathrm{kg}$ of compound $\mathrm{M} 1$ and rosiglitazone on blood glucose (A) and body weight (B) as compared with empty vehicle. The number of animals per group was five. ${ }^{\star} P$ value $<0.05$.

CYP2A6, CYP2D6 and CYP2E1 (Table 2). However, M1 was a relatively strong inhibitor of the CYP2C enzyme family $\left(\mathrm{IC}_{50}\right.$ values for CYP2C8, CYP2C9 and CYP2C19 were less than
$5 \mu \mathrm{M})$ and it appeared to exhibit partial inhibition of all three CYP3A4 substrates tested (Kenworthy et al. 1999). Maximum inhibition of $3 \mathrm{~A} 4$ varied depending on the substrate. For midazolam inhibition was $50-60 \% \quad\left(\mathrm{IC}_{50} \quad 0.60 \mu \mathrm{M}\right)$; for nifedipine inhibition was $85-90 \%\left(\mathrm{IC}_{50} 2 \cdot 4 \mu \mathrm{M}\right)$; and for testosterone inhibition was $70-80 \%\left(\mathrm{IC}_{50}\right.$ $1 \cdot 6 \mu \mathrm{M})$. Compared with M1, M2 was a less potent inhibitor of all the hepatic P450 enzymes examined (Table 2). In particular, there was little if any inhibition of the CYP2C enzymes other than CYP2C8, which was moderately inhibited by M2 $\left(\mathrm{IC}_{50} 6.9 \mu \mathrm{M}\right)$. M2 was 20-fold less potent at inhibiting CYP2C8 and at least 14-fold less potent at inhibiting CYP3A4 compared with M1. This suggests an important role in the methylester moiety in hepatic P450 inhibition.

\section{Discussion}

TZDs act as agonists of PPAR $\gamma$ (Schoonjans \& Auwerx 2000) and exert their antidiabetic effect by improving peripheral tissue insulin sensitivity, particularly in adipose tissue (Lehmann et al. 1995). During the last decade, an exhaustive search for novel agents based on the TZD ciglitazone (Shoda et al. 1982) has yielded three commercially marketed drugs: pioglitazone (Mosome et al. 1991), rosiglitazone (Cantello et al. 1994) and troglitazone. Troglitazone also lowers the excess androgens in women with PCOS (Azziz et al. 2001). As troglitazone directly inhibits the androgen biosynthetic enzymes P450c17 and 3ßHSDII at therapeutically achieved concentrations, but pioglitazone and rosiglitazone do not (Arlt et al. 2001), it is not yet apparent whether pioglitazone, rosiglitazone and other TZD drugs will exert a similar effect on the hyperandrogenism of PCOS. Therefore, we have sought to synthesize novel TZD drugs and examine the potential roles of different portions of the molecule on various physiologic variables.

We have previously shown, using various animal models (Dey et al. 1999), that the substituted $\alpha$-phenyl cinnamic acid derivative exerts a weak antihyperglycemic effect (Dey et al. 2001). Therefore, we postulated that linking this molecule with a 2,4-TZD moiety could provide compounds retaining the original glucose-lowering activity and, additionally, an affinity for PPAR $\gamma$, and that such 
Table 2 In vitro inhibition studies on hepatic P450 enzymes

P450
CYP1A2
CYP2A6
CYP2C8
CYP2C9
CYP2C19
CYP2D6
CYP2E1
CYP3A4
CYP3A4
CYP3A4

\begin{tabular}{l} 
Substrate \\
\hline Phenacetin \\
Coumarin \\
Paclitaxel \\
Diclofenac \\
Mephenytoin \\
Dextromethorphan \\
Chlozoxazone \\
Midazolam \\
Nifedipine \\
Testosterone
\end{tabular}

\begin{tabular}{l} 
M1 I $\mathbf{I C}_{\mathbf{5 0}}{ }^{*}$ \\
\hline $\mathrm{NI}$ \\
$>50$ \\
0.34 \\
0.88 \\
2.8 \\
$>50$ \\
$>20$ \\
$0.6 \dagger$ \\
2.43 \\
1.6
\end{tabular}

\begin{tabular}{l}
$\mathbf{M} 2 \mathbf{I C}_{\mathbf{5 0}}{ }^{*}$ \\
\hline $\mathrm{NI}$ \\
$>50$ \\
$6 \cdot 9$ \\
$>50$ \\
$>50$ \\
$\mathrm{NI}$ \\
$>50$ \\
$8 \cdot 6$ \\
$\mathrm{NI}$ \\
$>50$
\end{tabular}

\begin{tabular}{l}
$\begin{array}{l}\text { Positive } \\
\text { control IC } \text { 50 }^{*}\end{array}$ \\
\hline 2.8 \\
0.41 \\
1.4 \\
0.69 \\
11.2 \\
0.035 \\
3.6 \\
0.082 \\
0.17 \\
0.3
\end{tabular}

${ }^{*} \mathrm{IC}_{50}$ values in $\mu \mathrm{M}$; $\mathrm{NI}$, not inhibited; tmaximum inhibition was 50-60\%; łmaximum inhibition was $85-90 \%$; §maximum inhibition was $70-80 \%$.

compounds would be useful for treating type 2 diabetes. Our analysis of the five compounds synthesized suggests that compound M1 may hold therapeutic promise. Troglitazone, the first commercial TZD drug, was withdrawn from the market because of idiosyncratic hepatocellular injury due to inhibition of hepatic P450 enzymes by the drug and two of its metabolites (Yamazaki et al. 2000). Because troglitazone also inhibits steroidogenic P450c17 (Arlt et al. 2001), we examined the effects of these five compounds on $\mathrm{P} 450 \mathrm{c} 17$ and $3 \beta \mathrm{HSDII}$, and the effects of $\mathrm{Ml}$ on hepatic cytochrome $\mathrm{P} 450$ enzymes. These data showed that M1 was a poor inhibitor of $\mathrm{P} 450 \mathrm{c} 17$ but a moderate inhibitor of some hepatic P450 enzymes tested, while exerting strong PPAR $\gamma$ agonist activity.

Retention of PPAR $\gamma$ agonist activity, which is essential for the anti-diabetic actions of TZD drugs, required the presence of the cinnamic acid double bond (see activities of M1, 2 and 3 compared with M4 and M5). Both the nature of the scaffold or TZD side group and modifications to the TZD core itself can influence the actions of TZDs to inhibit steroidogenic enzymes, but changes in the scaffold are more important. This is seen with the differences between M3 and M5 compared with M2 and M4, and is consistent with the previously observed differences among tro-, pio- and rosiglitazone (Arlt et al. 2001), which contain the same TZD core but different side groups. When TZDs inhibit steroidogenic activities, the $17 \alpha$-hydroxylase and 17,20-lyase activities are inhibited similarly, as would be expected by the common active site for both reactions (Auchus \& Miller 1999) and the competitive mode of inhibition by TZD drugs (Arlt et al. 2001). By contrast, the inhibition of these two activities is not proportional to the inhibition of $3 \beta$-hydroxysteroid dehydrogenase activity, which is consistent with this activity being catalyzed by a different enzyme that is inhibited non-competitively by TZD drugs (Arlt et al. 2001).

Finally, the most remarkable aspect of these new TZD drugs is evidenced by a comparison of the data in vivo and in vitro. The compound M1 had only 3\% of PPAR $\gamma$ agonist activity of rosiglitazone in the transcriptional assay, yet both M1 and rosiglitazone exerted equivalent glucose-lowering activity in animal models of diabetes. This suggests that Ml is exerting some of its glucose-lowering effects by mechanisms independent of PPAR $\gamma$ activation. Based on our previous studies (Dey et al. 1999, 2001) we would suggest that this may be due to interaction of the cinnamic acid moiety with the insulin receptor. This observation indicates that bifunctional drugs can be designed that will elicit glucose-lowering effects at more than one cellular target.

\section{Acknowledgements}

This work was supported by NIH grant DK HD41958, and by a research grant from Calyx Therapeutics (to W.L.M.). W.A. is a Heisenberg Senior Clinical Fellow of the Deutsche Forschungsgemeinschaft (DFG; AR 310/3-1). 


\section{References}

Arlt W, Auchus RJ \& Miller WL 2001 Thiazolidinediones but not metformin directly inhibit the steroidogenic enzyme P450c17 and 3ß-hydroxysteroid dehydrogenase. Fournal of Biological Chemistry 276 16767-16771.

Auchus RJ \& Miller WL 1999 Molecular modeling of human $\mathrm{P} 450 \mathrm{c} 17$ (17 $\alpha$-hydroxylase/17 m20 lyase): insights into reaction mechanisms and effects of mutations. Molecular Endocrinology 13 1169-1182.

Auchus RJ, Lee TC \& Miller WL 1998 Cytochrome b5 augments the 17,20-lyase activity of human P450c17 without direct electron transfer. Fournal of Biological Chemistry 273 3158-3165.

Azziz R, Ehrmann D, Legro RS, Whitcomb RW, Hanley R, Fereshetian AG, O'Keefe M, \& Ghazzi MN 2001 Troglitazone improves ovulation and hirsutism in the polycystic ovary syndrome: a multicenter, double blind, placebo-controlled trial. fournal of Clinical Endocrinology and Metabolism 86 1626-1632.

Baldwin SJ, Clarke SE \& Chenery RS 1999 Characterization of the cytochrome $\mathrm{P} 450$ enzymes involved in the in vitro metabolism of rosiglitazone. British fournal of Pharmacology 48 424-432.

Cantello BC, Cawthorne MA, Haig D, Hindley RM, Smith SA \& Thurlby PL 1994 The synthesis of BRL 49653 - a novel and potent antihyperglycemic agent. Bioorganic Medicine and Chemistry Letters 4 1 181-1184.

Crespi CL \& Miller PV 1999 The use of heterologously expressed drug metabolizing enzymes - state of the art and prospects for the future. Pharmacology and Therapeutics 84 121-131.

Dey D, Medicherla S, Neogi P \& Nag B 1999 CLX-0901: a new class of orally active insulin sensitizer. Diabetes 48 Al19.

Dey D, Neogi P \& Nag B 2001 Evidence for the interaction of a small molecule with insulin receptor using surface plasmon resonance. FASEB Fournal 15 A526.

Dunaif A \& Thomas A 2001 Current concepts in the polycystic ovary syndrome. Annual Reviews in Medicine 52 401-419.

Dunaif A, Scott D, Finegood D, Quintana B \& Whitcomb R 1996 The insulin-sensitizing agent troglitazone improves metabolic and reproductive abnormalities in the polycystic ovary syndrome. Fournal of Clinical Endocrinology and Metabolism $\mathbf{8 1}$ 3299-3306.

Ehrmann DA, Barnes RB \& Rosenfield RL 1995 Polycystic ovary syndrome as a form of functional ovarian hyperandrogenism due to dysregulation of androgen secretion. Endocrine Reviews 16 322-353.

Ehrmann DA, Schneider DJ, Sobel BE, Cavaghan MK, Imperial J, Rosenfield RL \& Polonsky KS 1997 Troglitazone improves defects in insulin action, insulin secretion, ovarian steroidogenesis, and fibrinolysis in women with polycystic ovary syndrome. Fournal of Clinical Endocrinology and Metabolism 82 2108-2116.

Franks S 1995 Polycystic ovary syndrome. New England Fournal of Medicine 333 853-861.

Frost SC \& Lane DM 1985 Evidence for the involvement of vicinal sulfhydryl groups in insulin activated hexose transport by 3T3-L1 adipocytes. Fournal of Biological Chemistry 260 2646-2652.

Gietz D, St Jean A, Woods RA \& Schiestl RH 1992 Improved method for high efficiency transformation of intact yeast cells. Nucleic Acids Research 201425.

Hadfield C, Cashmore AM \& Meacock PA 1986 An efficient chloramphenicol-resistance marker for Saccharomyces cerevisiae and Escherichia coli. Gene 45 149-158.

Kenworthy KE, Bloomer JC, Clarke SE \& Houston JB 1999 CYP3A4 drug interactions: correlation of 10 in vitro probe substrates. British Fournal of Pharmacology 48 716-727.

Lee TC, Miller WL \& Auchus RJ 1999 Medroxyprogesterone acetate and dexamethasone are competitive inhibitors of different human steroidogenic enzymes. Fournal of Clinical Endocrinology and Metabolism 84 2104-2110.
Lehmann JM, Moore LB, Smith-Oliver TA, Wilkison WO, Willson TM \& Kliewer SA 1995 An antidiabetic thiazolidinedione is a high affinity ligand for peroxisome proliferator-activated receptor $\gamma(\operatorname{PPAR} \gamma)$. Fournal of Biological Chemistry 270 12953-12956.

Lin D, Harikrishna JA, Moore CCD, Jones KL \& Miller WL 1991 Missense mutation serine $106 \rightarrow$ proline causes $17 \alpha$-hydroxylase deficiency. Fournal of Biological Chemistry 266 15992-15998.

Lin D, Black SM, Nagahama Y \& Miller WL 1993 Steroid $17 \alpha$-hydroxylase and 17,20-lyase activities of P450c17: contributions of serine 106 and P450 reductase. Endocrinology 132 2498-2506.

Mosome Y, Meguro K, Ikeda H, Hatanaka C, Ot S \& Shoda T 1991 Studies on antidiabetic agents. X. Synthesis and biological activities of pioglitazone and related compounds. Chemistry and Pharmacology Bulletin 39 1440-1444.

Nakajima N, Kakamura S, Tokudome S, Shimada N, Yamazaki H \& Yokoi T 1999 Azelastine N-demethylation by cytochrome P-450 CYP3A4, CYP2D6, and CYP1A2 in human liver microsomes: evaluation of approach to predict the contribution of multiple CYPs. Drug Metabolism and Disposal 27 1381-1391.

Nakajin S, Shively JE, Yuan PM \& Hall PF 1981 Microsomal cytochrome P-450 from neonatal pig testis: two enzymatic activities (17 $\alpha$-hydroxylase and c17,20-lyase) associated with one protein. Biochemistry 20 4037-4042.

Obach RS 1999 Prediction of human clearance of twenty-nine drugs from hepatic microsomal intrinsic clearance data: an examination of in vitro half-life approach and nonspecific binding to microsomes. Drug Metabolism and Disposal 27 1350-1359.

Olefsky JM 2000 Treatment of insulin resistance with peroxisome proliferator-activated receptor $\gamma$ agonists. Fournal of Clinical Investigation 106 467-472.

Pompon D, Louerat B, Bronine A \& Urban P 1996 Yeast expression of animal and plant $\mathrm{P} 450$ s in optimized redox environments. Methods of Enzymology 272 51-64.

Primer A 2000 Animal models of diabetes. In Animal Models of Diabetes, pp 63-109. Eds A Sima \& E Shafir. London: Harwood Academic.

Rendic S \& Di Carlo FJ 1997 Human cytochrome P450 enzymes: a status report summarizing their reactions, substrates, inducers, and inhibitors. Drug Metabolism Reviews 29 414-580.

Rhéaume E, Simard J, Morel Y, Mebarki F, Zachmann M, Forest MG, New MI \& Labrie F 1992 Congenital adrenal hyperplasia due to point mutations in the type II $3 \beta$-hydroxysteroid dehydrogenase gene. Nature Genetics 1 239-245.

Schoonjans K \& Auwerx J 2000 Thiazolidinediones: an update. Lancet 355 1008-1010.

Shoda T, Mizuno K, Imamiya E, Sugiyama Y, Fujita T \& Kawamatsu Y 1982 Studies on antidiabetic agents. II. Synthesis of 5-[4-(1-methylcyclohexylmethoxy)-benzyl] thiazolidine-2,4-dione (ADD-3878) and its derivatives. Chemistry and Pharmacology Bulletin $303580-3600$.

Spiegelman BM 1998 PPAR- $\gamma$ : adipogenic regulator and thiazolidinedione receptor. Diabetes 47 507-514.

Tafuri SR 1996 Troglitazone enhances differentiation, basal glucose uptake and Glut1-protein levels in 3T3-L1 adipocytes. Endocrinology $1374706-4712$.

Thomas JL, Myers RP \& Strickler RC 1989 Human placental 3 $\beta$-hydroxy-5-ene-steroid dehydrogenase and steroid $\Delta 5 \rightarrow \Delta 4$-ene-isomerase: purification from mitochondria and kinetic profiles, biophysical characterization of the purified mitochondrial and microsomal enzymes. Fournal of Steroid Biochemistry 33 209-217.

Yamazaki H, Suzuki M, Tane K, Shimada N, Nakajima M \& Yoko T 2000 In vitro inhibitory effects of troglitazone and its metabolites on drug oxidation activities of human cytochrome P450 enzymes: comparison with pioglitazone and rosiglitzone. Xenobiotica 20 $61-70$. 
Zuber MX, Simpson ER \& Waterman MR 1986 Expression of bovine $17 \alpha$-hydroxylase cytochrome P-450 cDNA in nonsteroidogenic (COS 1) cells. Science 234 1258-1261.
Received in final form 12 December 2003 Accepted 12 January 2004 